\title{
Mata Atlântica: patrimônio natural, cultural e biológieo do Brasil
}

Recebido: 31/10/2016. Aprovado: 16/11/2016.

\author{
Elis Regina Mazzurana*
}

Resumo: A Mata Atlântica é uma das áreas com maior biodiversidade do planeta, o que faz dela uma das áreas prioritárias em conservação. Este trabalho tem por objetivo fazer uma análise a respeito da importância natural, cultural e biológica da Mata Atlântica, descrevendo as consequências da destruição da mata ao ser humano, bem como, apresentando algumas das medidas que estão sendo tomadas para conservação dos remanescentes florestais e recuperação de áreas degradadas. A devastação da Mata Atlântica é ocasionada principalmente pela ação antrópica, já que grande parte da população brasileira vive nesse território, ocasionando impactos diretos à biodiversidade. Nas últimas décadas, algumas leis foram promulgadas com o objetivo de recuperar as áreas degradadas e preservar os remanescentes florestais. Além disso, há várias ONG'S que atuam em prol da floresta. Entretanto, muito ainda precisa ser feito para que se tenha um resultado efetivo na recuperação e conservação da mata.

Palavras-chave: Mata Atlântica. Biodiversidade. Conservação.

Abstract: The Atlantic Forest is one of the areas with the greatest biodiversity on the planet, making it one of the priority areas for conservation. This paper aims to make an analysis about the natural importance, cultural and biological of the Atlantic Forest, describing the consequences of the destruction of the forest to humans as well, featuring some of the measures being taken for conservation of forest remnants and recovery of degraded areas. The devastation of the Atlantic Forest is mainly caused by human action, since much of the Brazilian population lives in this territory, causing direct impacts on biodiversity. In recent decades, some laws have been enacted in order to recover degraded areas and to preserve the remaining forests. In addition, there are several NGO's working in favor of the forest. However, much remains to be done in order to have an effective result in the recovery and conservation of the forest.

Keywords: Atlantic forest. Biodiversity. Conservation.

* Mestra em Produção Vegetal pela Universidade do Estado de Santa Catarina (UDESC), Florianópolis. Professora do Ensino Superior da Universidade Alto Vale do Rio do Peixe (UNIARP). 


\section{Introdução}

A história brasileira está intimamente ligada ao bioma Mata Atlântica, que se encontra extremamente ameaçado pela ação humana, sendo um dos maiores repositórios de biodiversidade do mundo e estando entre as mais importantes áreas de conservação da biodiversidade do planeta, considerado um hotspot mundial.

É no território da Mata Atlântica que vive a maior parte da população brasileira, utilizando desse espaço para atividades de subsistência, como agricultura, agropecuária, extrativismo, industrialização, ocupação e expansão urbana desordenada, gerando grande impacto aos ecossistemas, o que resultou em perda da biodiversidade, além da degradação e poluição dos recursos naturais oferecidos pela floresta. Nos últimos anos, a população vem sentindo as consequências causadas por essa devastação do meio ambiente, principalmente em relação à água, que se encontra escassa e/ou poluída em muitas regiões da Mata Atlântica.

Este trabalho tem por objetivo fazer uma análise a respeito da importância natural, cultural e biológica da Mata Atlântica, descrevendo as consequências da destruição da mata ao ser humano, bem como, apresentando as medidas que estão sendo tomadas para conservação dos remanescentes florestais e recuperação de áreas degradadas.

\section{Biomas brasileiros: a Mata Atlântica}

O Brasil é um dos países que contém a maior biodiversidade do planeta, abrigando $20 \%$ do número total de espécies da Terra. Apresenta, ainda, seis biomas com características muito distintas: Amazônia, Caatinga, Cerrado, Mata Atlântica e Pantanal; sendo dois deles, o Cerrado e a Mata Atlântica, considerados hotspots mundiais ${ }^{1}$.

O termo hotspots foi criado 1988, pelo ecólogo inglês Norman Myers, para classificar os locais com uma grande riqueza natural e uma elevada biodiversidade, mas que, no entanto, encontram-se ameaçados de extinção ou passam por um corrente processo de degradação, indicando que a conservação desses locais é mais urgente. Hotspot é, portanto,

1 MMA-Ministério do Meio Ambiente. Mata Atlântica. Disponível em: <http://www.mma. gov.br/biomas/mata-atlantica>. Acesso em: 09 out. 2016. 
toda área prioritária para conservação, isto é, de alta biodiversidade e endemismo e ameaçada no mais alto grau².

A organização não-governamental Conservação Internacional (CI) monitora os hotspots desde 1996, sendo que na última atualização, em 2005, foi divulgado um relatório com 34 regiões do planeta identificadas como hotspots, estando a Mata Atlântica em primeiro lugar entre áreas prioritárias para conservação ${ }^{3}$. Desta forma, a Mata Atlântica torna-se uma área mundialmente importante em termos de conservação da biodiversidade.

A região de Mata Atlântica, inicialmente, apresentava cerca de 1.300.000 $\mathrm{Km}^{2}$ estendendo-se por dezessete estados do território brasileiro, sendo eles: Rio Grande do Sul, Santa Catarina, Paraná, São Paulo, Goiás, Mato Grosso do Sul, Rio de Janeiro, Minas Gerais, Espírito Santo, Bahia, Alagoas, Sergipe, Paraíba, Pernambuco, Rio Grande do Norte, Ceará e Piauí. Atualmente, apenas cerca de 7\% do bioma Mata Atlântica com extensão acima de 100 hectares estão bem conservados ${ }^{4}$.

O bioma Mata Atlântica é formado por um conjunto de formações florestais, como floresta ombrófila (densa, mista e aberta), floresta estacional semidecidual e estacional decidual, manguezais, restingas e campos de altitude associados, brejos interioranos no Nordeste, além das conhecidas florestas com Araucaria angustifolia (ombrófila mista) que ocorrem nos planaltos da região Sul situados a oeste da Serra do Mar5 .

Apesar de estar muito reduzida e fragmentada, estima-se que na Mata Atlântica existam cerca de 20.000 espécies vegetais (cerca de 35\% das espécies existentes no Brasil), incluindo diversas espécies endêmicas e ameaçadas de extinção. Essa riqueza é maior que a de alguns países. Por isso, a região da Mata Atlântica é altamente prioritária para a conservação da biodiversidade mundial. Em relação à fauna, os levantamentos já realizados indicam que a Mata Atlântica abriga 849 espécies de aves, 370

2 CAMPANILI, Maura; SCHAFFER, Wigold Bertoldo (Orgs.). Mata Atlântica: patrimônio nacional dos brasileiros. Ministério do Meio Ambiente. Secretaria de Biodiversidade e Florestas. Núcleo Mata Atlântica e Pampa. Brasília: MMA, 2010.

$3 \mathrm{Cl}$ - Conservation International. Hotspots. Disponível em: <http://www.conservation. org/>. Acesso em: 09 out. 2016.

4 MMA, 2016.

5 SNIF - Sistema Nacional de Informações Florestais. Os biomas e suas florestas. Disponível em: <http://www.florestal.gov.br/snif/recursos-florestais/os-biomas-e-suas-florestas>. Acesso em: 11 out. 2016. 
espécies de anfíbios, 200 espécies de répteis, 270 de mamíferos e cerca de 350 espécies de peixes ${ }^{6}$. Além disso, ela desempenha um papel importante no ciclo global do carbono, e seu manejo ou sua destruição podem afetar de forma significativa o curso do aquecimento global no século XXI, já que as florestas influenciam e são influenciadas pelas mudanças climáticas?

Outro aspecto fundamental, é que a Mata Atlântica regula o fluxo dos mananciais hídricos, assegura a fertilidade do solo, controla o clima e protege escarpas e encostas das serras, preserva um patrimônio natural e cultural imenso, além de diversos rios que abastecem as cidades e metrópoles brasileiras nascerem nesse bioma ${ }^{8}$. Desta forma, foi decretada Reserva da Biosfera pela Unesco e Patrimônio Nacional, pela Constituição Federal de $1988^{9}$.

Apesar de toda a sua importância biológica e justamente por ser o bioma onde vive a maior parte dos brasileiros, a Mata Atlântica encontra-se ameaçada por essa ocupação humana, devido principalmente às atividades de agricultura e agropecuária; exploração predatória de madeira e espécies vegetais; industrialização e expansão urbana desordenada; consumo excessivo, lixo e poluição ${ }^{10}$.

\subsection{Consequências da devastação da Mata Atlântica}

A destruição e utilização irracional da Mata Atlântica iniciou no ano 1500 , com a chegada dos Europeus. O pau-brasil foi o principal alvo de extração e exportação dos exploradores, o que levou o Brasil a ser conhecido como "Terra Brasilis", devido à coloração avermelhada da madeira. Atualmente, o pau-brasil está quase extinto, além de outras madeiras de valor que também foram exploradas até a beira da extinção, como o tapinhoã, sucupira, canela, canjarana, jacarandá, araribá, pequi, jenipaparana, peroba, urucurana e vinhático ${ }^{11}$.

6 MMA, 2016.

7 SNIF, 2016.

8 VARJABEDIAN, Roberto. Lei da Mata Atlântica: retrocesso ambiental. Estudos Avançados, v. 24, n. 68, p. 147-160, 2010.

9 SOS Mata Atlântica. Florestas: a Mata Atlântica. Disponível em: <https://www.sosma. org.br/nossa-causa/a-mata-atlantica/>. Acesso em: 09 out. 2016.

10 SOS Mata Atlântica, 2016.

11 IB Florestas - Instituto Brasileiro de Florestas. Bioma Mata Atlântica. Disponível em: <http://www.ibflorestas.org.br/bioma-mata-atlantica.html>. Acesso em: 09 out. 2016. 
A Mata Atlântica permite atividades essenciais para a nossa economia, como a agricultura, a pesca, o extrativismo, o turismo, a geração de energia e o lazer, melhorando a qualidade de vida dos brasileiros por oferecer ótimos espaços coletivos que propiciam o lazer e a prática de esportes e exercícios ${ }^{12}$. Por outro lado, todos os principais ciclos econômicos desde a exploração da madeira, plantio de culturas como o café, cana-de-açúcar, soja, fumo, instalação de indústrias e a crescente população, foram desalojando a Mata Atlântica. Historicamente, nenhum dos setores agropecuário, madeireiro, siderúrgico ou imobiliário se preocupou com a conservação da biodiversidade e a manutenção das florestas ${ }^{13}$.

Aproximadamente $70 \%$ do PIB brasileiro é oriundo da região da Mata Atlântica, onde vivem cerca de 120 milhões de habitantes ${ }^{14}$, resultando em grande pressão sobre a biodiversidade e os recursos hídricos desse bioma, que já enfrenta em diversas regiões problemas de crise hídrica, associados à escassez, ao desperdício, à má utilização da água, ao desmatamento e à poluição ${ }^{15}$.

De acordo com estudos realizados pela Fundação SOS Mata Atlântica e o Instituto de Pesquisas Espaciais (INPE), houve "desmatamento de 18.433 hectares (ha), ou $184 \mathrm{Km}^{2}$, de remanescentes florestais nos 17 Estados da Mata Atlântica no período de 2014 a 2015, um aumento de apenas 1\% em relação ao período anterior (2013-2014), que registrou 18.267 há" 16 .

Entre os estados que mais desmatam estão Minas Gerais, Piauí e Bahia. O Paraná também se encontra em estado de atenção, pois foi o que apresentou o aumento mais brusco, sendo que o retorno do desmatamento nas florestas com araucária é o principal ponto de alerta, responsável por $89 \%$ (1.777 ha) do total de desflorestamento no estado paranaense no período 2014-2015. Restam somente 3\% das florestas que abrigam a Araucaria angustifolia, espécie ameaçada de extinção, conhecida também como pinheiro brasileiro ou pinheiro-do-paraná ${ }^{17}$.

\footnotetext{
SOS Mata Atlântica, 2016.

3 CAMPANILI; SCHAFFER, 2010.

14 MMA, 2016

15 IB Florestas, 2016.

16 SOS Mata Atlântica, 2016.

17 SOS Mata Atlântica, 2016.
} 
"Atualmente, o crescimento urbano e o consumo dos recursos é o principal fator de degradação da Mata Atlântica, além da falta de políticas públicas que incentivem seu uso sustentável" ${ }^{18}$.

Além do patrimônio vegetal e animal, a Mata Atlântica

abriga grande diversidade cultural, constituida por povos indigenas, como os Guaranis, e culturas tradicionais não-indígenas como os caiçaras, os quilombolas, os roceiros e os caboclos ribeirinhos. Essas populações tradicionais têm uma relação profunda com o ambiente em que vivem, porque dele são diretamente dependentes ${ }^{19}$.

Mesmo com a grande diversidade cultural e conhecimento a respeito da natureza que esses povos abrigam, durante todo o período de exploração da mata, foram muitas vezes expulsos de seu território original ou expurgados de grande parte deles, sendo os primeiros habitantes do Brasil a sofrer as graves consequências que a destruição da mata nos traz $^{20}$. Atualmente, há várias áreas indígenas demarcadas no território da Mata Atlântica. Entretanto, essas áreas continuam sendo exploradas com fins econômicos, por meio de atividades como a extração da madeira ou extração mineral ${ }^{21}$.

A floresta é fundamental para os processos de manutenção dos recursos hídricos, assegurando a quantidade e qualidade necessária de água potável para milhões de brasileiros, sendo que o maior reservatório subterrâneo de água doce do mundo, o Aquífero Guarani, tem grande parte de sua área no domínio da Mata Atlântica. A utilização das águas de modo consciente e sustentável, com a conservação das condições que garantem a qualidade da água, são os principais fatores que estão intimamente ligados à proteção do Aquífero, e pelo fato da Mata Atlântica estar sobre esse imenso manancial subterrâneo, o último fator deve estar intimamente ligado à conservação da floresta ${ }^{22}$.

18 IB Florestas, 2016.

19 CAMPANILI; SCHAFFER, 2010, p. 92-93.

20 CAMPANILI; SCHAFFER, 2010.

21 ANDRADE, Lúcia Mendonça Morato de. Terras indígenas na Mata Atlântica: pressões e ameaças. Comissão Pró-Índio de São Paulo: São Paulo, 2013.

22 SANTOS, Rodolfo Cristiano Martins. Mata Atlântica: características, biodiversidade e a história de um dos biomas de maior prioridade para conservação e preservação de seus ecossistemas. 2010. TCC (Graduação) - Centro Universitário Metodista Izabela Hendrix, Belo Horizonte. 
A expansão da fronteira agrícola em áreas de floresta tem sido usada historicamente como válvula de escape para acomodar esse excedente populacional. Assim, a Mata Atlântica continua sendo devastada para que se possa acomodar os conflitos de terra sem que uma reforma agrária seja efetuada nas áreas já ocupadas. Contudo, nas novas áreas ocupadas reproduz-se o mesmo padrão de concentração fundiária. Assim, após algum tempo, a incapacidade de absorção de novos excedentes recria as condições para um novo fluxo de migração para áreas de floresta ainda não convertidas ${ }^{23}$.

É importante lembrarmos que as consequências da degradação da Mata Atlântica vão muito além da perda da biodiversidade, pois,

sem as matas ciliares, os rios, lagos e represas ficarão cada vez mais poluídos e assoreados, inviabilizando a agricultura e o abastecimento de água para a população. Sem a vegetação nos topos de morro e áreas muito íngremes, populações inteiras ficam à mercê da sorte em épocas de chuvas, quando as encostas desprotegidas deslizam e vêm abaixo sem dó nem piedade, causando inúmeros prejuízos econômicos, sociais e ambientais ${ }^{24}$.

Desta forma, podemos perceber que manter o que ainda resta da Mata Atlântica e recuperar o máximo possível de áreas degradadas, é a única forma de não comprometermos o futuro da vida humana nas cidades e no campo.

\subsection{Programas para conservação e recuperação da Mata Atlântica}

De acordo com a Constituição Federal de 1988, em seu art. 225,

todos têm direito ao meio ambiente ecologicamente equilibrado, bem de uso comum do povo e essencial à sadia qualidade de vida, impondo-se ao Poder Público e à coletividade o dever de defendê-lo e preservá-lo para as presentes e futuras gerações ${ }^{25}$.

23 YOUNG, Carlos Eduardo Frickmann. Aspectos sociais e econômicos do desmatamento em áreas de Mata Atlântica. Projeto "Hotspots". Disponível em: <http://www.ie.ufrj.br/ images/gema/Gema_Artigos/2001/aspect.pdf>. Acesso em: 23 out. 2016.

CAMPANILI; SCHAFFER, 2010, p. 16-17.

25 BRASIL. Constituição da República Federativa do Brasil de 1988. Disponível em: <http://www.planalto.gov.br/ccivil_03/Constituicao/Constituicao.htm>. Acesso em: 09 out. 2016. 
Baseando-se nesse artigo da constituição federal, percebemos que cabe ao poder público e também a toda a população a conservação do meio ambiente. Desta forma, foram e continuam sendo criadas as Unidades de Conservação (UC), que são áreas com características naturais relevantes, legalmente instituídas pelo poder público, com objetivos de conservação da natureza. De acordo com o Ministério do Meio Ambiente

são as unidades de conservação que melhor traduzem a missão de contribuir para a proteção da biodiversidade brasileira, principalmente de espécies endêmicas e ameaçadas de extinção, além de ajudar a regular o clima, abastecer os mananciais de água, melhorar a qualidade de vida das pessoas e, muitas vezes, abrigar populações tradicionais, cujo sustento depende da utilização sustentável de seus recursos naturais. Outro importante papel das unidades de conservação é contribuir com a geração de emprego e renda, principalmente através da exploração adequada de seu potencial turístico ${ }^{26}$.

A primeira unidade de conservação criada oficialmente no Brasil foi o Parque Nacional de Itatiaia, em 1937, no limite dos estados de Minas Gerais, São Paulo e Rio de Janeiro ${ }^{27}$. Considerando a grande diversidade de formações vegetais presentes nos biomas Mata Atlântica e Campos Sulinos, foram indicadas 147 áreas prioritárias para conservação, sendo 79 de extrema importância biológica, onde cerca de $48 \%$ das áreas propostas estão na região Nordeste, principalmente nos estados da Bahia, do Ceará, de Alagoas e de Pernambuco. De modo geral, as áreas são de pequena extensão, o que reflete a fragmentação existente na Mata Atlântica da região, em parte decorrente de causas naturais (formações florestais em meio ao semiárido, "brejos" e "encraves"), e também devido à ocupação humana e seu consequente impacto sobre a vegetação ${ }^{28}$.

O código florestal brasileiro, instituído pela Lei ${ }^{\circ} 12.651$, de 25 de maio de 2012, dispõe sobre a proteção da vegetação nativa, estabelecendo

normas gerais sobre a proteção da vegetação, áreas de Preservação Permanente e áreas de Reserva Legal; a exploração florestal, o suprimento de matéria-prima florestal, o controle da origem dos produtos florestais

26 MMA, 2016.

27 CAMPANILI; SCHAFFER, 2010.

28 MMA - Ministério do Meio Ambiente. Avaliação e identificação de áreas e ações prioritárias para a conservação, utilização sustentável e repartição dos benefícios da biodiversidade dos biomas brasileiros. Brasília: MMA/SBF, 2002. 
e o controle e prevenção dos incêndios florestais, e prevê instrumentos econômicos e financeiros para o alcance de seus objetivos.

A Lei $n^{\circ}$ 9.985, de 18 de julho de 2000, institui o Sistema Nacional de Unidades de Conservação da Natureza, que permite destinar áreas de florestas como Reservas Particulares do Patrimônio Natural (RPPNs), onde é permitida a pesquisa científica e a visitação com objetivos turísticos, recreativos e educacionais, garantindo a conservação da biodiversidade, dos recursos hídricos, e possibilitando que a população possa apreciar as belezas oferecidas pela natureza ${ }^{29}$. AS RPPNs da Mata Atlântica protegem cerca de 1.152,95 km², permitindo a preservação de muitas espécies animais e vegetais ${ }^{30}$.

Para assegurar a proteção do bioma Mata Atlântica e ao mesmo tempo garantir a utilização dos recursos naturais pelo ser humano como forma de subsistência, foi criada a Lei ${ }^{0} 11.428$, de 22 de dezembro de 2006, que dispõe sobre a utilização e proteção da vegetação nativa do Bioma Mata Atlântica, regulamentada pelo Decreto $n^{\circ} 6.660$, de 21 de novembro de 2008.

De acordo com o art. 6o, da Lei $n^{\circ} 11.428$,

a proteção e a utilização do Bioma Mata Atlântica têm por objetivo geral o desenvolvimento sustentável e, por objetivos especificos, a salvaguarda da biodiversidade, da saúde humana, dos valores paisagísticos, estéticos e turísticos, do regime hídrico e da estabilidade social ${ }^{31}$.

Parágrafo único. Na proteção e na utilização do Bioma Mata Atlântica, serão observados os princípios da função socioambiental da propriedade, da equidade intergeracional, da prevenção, da precaução, do usuário-pagador, da transparência das informações e atos, da gestão democrática, da celeridade procedimental, da gratuidade dos serviços administrativos prestados ao pequeno produtor rural e às populações tradicionais, e do respeito ao direito de propriedade ${ }^{32}$.

$29 \quad$ BRASIL. Lei $n^{\circ}$ 9.985, de 18 de julho de 2000. Disponível em: <http://www.planalto. gov.br/ccivil_03/leis/L9985.htm>. Acesso em: 23 out. 2016.

30 CAMPANILI; SCHAFFER, 2010.

31 BRASIL. Lei $n^{\circ}$ 11.428, de 22 de dezembro de 2006. Disponível em: <http://www. planalto.gov.br/ccivil_03/_ato2004-2006/2006/lei/l11428.htm>. Acesso em: 09 out. 2016. 
Há também o auxílio das organizações não-governamentais como a Fundação SOS Mata Atlântica e ONG's internacionais como a WWF e a Conservation International (CI), que atuam na conservação da Mata Atlântica de diversas formas: colaborando na definição de um método e sua aplicação, possibilitando a identificação de prioridades para a proteção da Mata Atlântica, apoiando movimentos contra agressões ao ecossistema e desenvolvendo projetos de educação ambiental.

A Fundação SOS Mata Atlântica surgiu em 1986 tendo como missão

promover a conservação da diversidade biológica e cultural do Bioma Mata Atlântica e ecossistemas sob sua influência, estimulando ações para o desenvolvimento sustentável, bem como promover a educação e o conhecimento sobre a Mata Atlântica, mobilizando, capacitando e estimulando o exercício da cidadania socioambiental ${ }^{3}$.

$A$ entidade desenvolve projetos de conservação ambiental, produção de dados, mapeamento e monitoramento da cobertura florestal do Bioma, campanhas, estratégias de ação na área de políticas públicas, programas de educação ambiental e restauração florestal, voluntariado, desenvolvimento sustentável e proteção e manejo de ecossistemas ${ }^{34}$.

Apesar do esforço dos governos federal, estaduais, municipais e também da iniciativa privada para criação e manutenção de áreas protegidas de Mata Atlântica, a maior parte dos remanescentes de vegetação nativa ainda permanece sem proteção. Assim, as estratégias para a conservação da biodiversidade visam contemplar também formas inovadoras de incentivos para a conservação e uso sustentável da floresta, tais como a promoção da recuperação de áreas degradadas e do uso sustentável da vegetação nativa, bem como o incentivo ao pagamento pelos serviços ambientais prestados pela Mata Atlântica ${ }^{35}$.

Levando em consideração o fato de que, como já observado anteriormente, a maior parte da população brasileira vive na região da Mata Atlântica, é muito importante a conservação dos remanescentes vegetais e também a recuperação de áreas degradadas, para assegurar a qualidade de vida desses quase $67 \%$ da população brasileira, pois são os remanescentes que mantêm as nascentes e fontes, regulam o fluxo dos

33 SOS Mata Atlântica, 2016.

34 SOS Mata Atlântica, 2016.

35 CAMPANILI; SCHAFFER, 2010. 
mananciais de água que abastecem as cidades e comunidades do interior, ajudam a regular o clima, a temperatura do solo e protegem escarpas e encostas de morros ${ }^{36}$.

Uma das formas mais eficientes para assegurar a conservação da Mata Atlântica pelas pessoas que vivem nesse território é a educação ambiental, que está amparada pelo art. 225 da Constituição Federal: "promover a educação ambiental em todos os níveis de ensino e a conscientização pública para a preservação do meio ambiente ${ }^{37}$ ". A educação ambiental no Brasil é assegurada pela Lei $n^{\circ} 9.795$, de 27 de abril de 1999, que trata da Política Nacional de Educação Ambiental, pois é só por meio da educação ambiental que o indivíduo poderá construir “" [...] valores sociais, conhecimentos, habilidades, atitudes e competências voltadas para a conservação do meio ambiente $[\ldots]^{38}$.

É importante ressaltar que, apesar da promulgação de leis que estabelecem alternativas para conservação e uso da floresta, só conseguiremos alcançar bons resultados por meio da educação ambiental, que auxilia no sentido de conscientizar a população quanto à importância da biodiversidade e da conservação do meio ambiente, fazendo com que as pessoas tomem atitudes em relação a isso.

\section{Considerações finais}

O Brasil apresenta ao todo seis biomas, com características muito distintas, sendo o bioma Mata Atlântica o mais devastado de todos. Os dados nos mostram que atualmente restam apenas cerca de $7 \%$ das florestas originais de Mata Atlântica, sendo que mais de $60 \%$ da população brasileira vive no domínio desse bioma, produzindo em torno de $70 \%$ do PIB. Devido à sua grande biodiversidade e importância biológica, a Mata Atlântica faz parte do patrimônio da Unesco e é considerada a número um dos hotspots mundiais. Entretanto, continua sendo degradada, e poucas áreas estão em processo de recuperação.

Ao analisar esses dados, conseguimos entender o porquê do bioma estar tão devastado e continuar ameaçado, pois é justamente no domínio

\footnotetext{
36 CAMPANILI; SCHAFFER, 2010

37 BRASIL, 1988.

38 BRASIL. Lei $n^{\circ}$ 9.795, de 27 de abril de 1999. Disponível em: <http://www.planalto. gov.br/ccivil_03/leis/L9795.htm>. Acesso em: 09 out. 2016.
} 
da Mata Atlântica que ocorre a maior geração de renda do Brasil. A explosão demográfica e consequente exploração do território de mata para atividades que sustentam o ser humano fizeram, e continuam fazendo, com que a Mata Atlântica seja explorada ao máximo. Entretanto, mesmo considerando a importância da agricultura para alimentar a crescente população, a mata continua sendo devastada sem que ocorra uma reforma agrária em áreas já ocupadas, fazendo com que voltemos sempre ao ponto inicial: explosão demográfica e a agricultura para alimentar a população, quando na verdade as áreas continuam concentrando-se nas mãos dos grandes latifundiários.

Nos últimos anos, algumas medidas têm sido tomadas como forma de conservação da Mata Atlântica, como a Lei n ${ }^{\circ} 11.428$, de 22 de dezembro de 2006, que dispõe sobre a utilização e proteção da vegetação nativa do Bioma Mata Atlântica, e permite que a população possa retirar recursos para subsistência diretamente da mata, de forma sustentável e preservando a biodiversidade. Porém, apesar da existência da lei, há falta de políticas públicas para incentivo do uso sustentável dos recursos oferecidos pela mata.

O código florestal brasileiro é um grande aliado das florestas, garantindo a delimitação e recuperação das áreas de preservação permanente e das áreas verdes. Apesar disso, não há fiscalização suficiente para assegurar que essas áreas sejam preservadas ou recuperadas, sendo mais um entrave na garantia da conservação das florestas. Da mesma forma, a criação das unidades de conservação é essencial para a conservação dos remanescentes de florestas, pois há remanescentes de vegetação nativa potencialmente ricos em biodiversidade e que ainda não estão contemplados pelas unidades de conservação, ficando a mercê da exploração.

Deve-se lembrar que conservação do meio ambiente, economia e aspectos sociais são vertentes que caminham juntas. Não é possível garantir a conservação do meio ambiente sem políticas públicas que permitam que todos possam viver com qualidade de vida, sem que, para isso, tenham que utilizar de forma inadequada os recursos oferecidos pela floresta. Outro aspecto importante que deve ser considerado é que não devemos nos ater somente aos números econômicos do país: quando falamos em conservação do meio ambiente, estamos falando de garantir que todos possam viver com qualidade de vida, em um ambiente limpo, saudável, com água potável e rico em biodiversidade, para que possamos apreciar tudo o que a natureza nos oferece. 
Desta forma, pode-se perceber que recuperar a Mata Atlântica vai muito além de manter o patrimônio natural, cultural e biológico que ela fornece; preservar os remanescentes de floresta e recuperar o maior número de áreas degradadas possível, é uma questão de sobrevivência humana, é garantir o futuro da população.

\section{Referências}

ANDRADE, Lúcia Mendonça Morato de. Terras indígenas na Mata Atlântica: pressões e ameaças. Comissão Pró-Índio de São Paulo: São Paulo, 2013.

BRASIL. Constituição da República Federativa do Brasil de 1988. Disponível em: <http://www.planalto.gov.br/ccivil_03/Constituicao/ Constituicao.htm>. Acesso em: 09 out. 2016.

. Lei $n^{\circ}$ 9.795, de 27 de abril de 1999. Disponível em: <http:// www.planalto.gov.br/ccivil_03/leis/L9795.htm>. Acesso em: 09 out. 2016.

. Lei $n^{\circ}$ 9.985, de 18 de julho de 2000. Disponível em: <http:// www.planalto.gov.br/ccivil_03/leis/L9985.htm>. Acesso em: 23 out. 2016.

. Lei $n^{\circ} 11.428$, de 22 de dezembro de 2006. Disponível em: $<$ http://www.planalto.gov.br/ccivil_03/_ato2004-2006/2006/lei/111428. htm>. Acesso em: 09 out. 2016.

CAMPANILI, Maura; SCHAFFER, Wigold Bertoldo (Orgs.). Mata Atlântica: patrimônio nacional dos brasileiros. Ministério do Meio Ambiente. Secretaria de Biodiversidade e Florestas. Núcleo Mata Atlântica e Pampa. Brasília: MMA, 2010.

CI-Conservation International. Hotspots. Disponível em: $<$ http://www. conservation.org/>. Acesso em: 09 out. 2016.

IB Florestas - Instituto Brasileiro de Florestas. Bioma Mata Atlântica. Disponível em: <http://www.ibflorestas.org.br/bioma-mata-atlantica. html>. Acesso em: 09 out. 2016.

MMA - Ministério do Meio Ambiente. Avaliação e identificação de áreas e ações prioritárias para a conservação, utilização sustentável e repartição dos benefícios da biodiversidade dos biomas brasileiros. Brasília: MMA/SBF, 2002. 
MMA - Ministério do Meio Ambiente. Mata Atlântica. Disponível em: $<$ http://www.mma.gov.br/biomas/mata-atlantica $>$. Acesso em: 09 out. 2016.

SANTOS, Rodolfo Cristiano Martins. Mata Atlântica: características, biodiversidade e a história de um dos biomas de maior prioridade para conservação e preservação de seus ecossistemas. 2010. TCC (Graduação) - Centro Universitário Metodista Izabela Hendrix, Belo Horizonte.

SNIF - Sistema Nacional de Informações Florestais. Os biomas e suas florestas. Disponível em: <http://www.florestal.gov.br/snif/recursos-florestais/os-biomas-e-suas-florestas>. Acesso em: 11 out. 2016.

SOS Mata Atlântica. Florestas: a Mata Atlântica. Disponível em: $<$ https://www.sosma.org.br/nossa-causa/a-mata-atlantica/>. Acesso em: 09 out. 2016.

VARJABEDIAN, Roberto. Lei da Mata Atlântica: retrocesso ambiental. Estudos Avançados, v. 24, n. 68, p. 147-160, 2010.

YOUNG, Carlos Eduardo Frickmann. Aspectos sociais e econômicos do desmatamento em áreas de Mata Atlântica. Projeto "Hotspots". Disponível em: <http://www.ie.ufrj.br/images/gema/Gema_Artigos/2001/ aspect.pdf $>$. Acesso em: 23 out. 2016.

E-mail da autora: elismazzurana@gmail.com 